\title{
Metastatic Cancer of Cowper's Gland: A Rare Cancer Managed Successfully by Molecular Profiling
}

\author{
Charles E. Myers $^{a} \quad$ Zoran Gatalica $^{b} \quad$ Anthony Spinelli $^{c} \quad$ Michael Castro $^{b}$ \\ Erica Linden ${ }^{d}$ Oliver Sartor ${ }^{\mathrm{e}}$ Mathew Sargent ${ }^{\mathrm{b}}$ \\ ${ }^{a}$ Foundation for Cancer Research and Education, Earlysville, Va., ${ }^{b}$ Caris Life Sciences, \\ Phoenix, Ariz., 'Department of Interventional Radiology, Martha Jefferson Hospital, \\ Charlottesville, Va., 'Department of Medicine, Massachusetts General Hospital, \\ Boston, Mass., and ${ }^{\mathrm{e}}$ Tulane Cancer Center, Tulane University School of Medicine, \\ New Orleans, La., USA
}

\section{Key Words}

Cowper's gland $\cdot$ Adenoid cystic carcinoma $\cdot \mathrm{c}$-kit $\cdot$ Molecular profiling

\begin{abstract}
Cancer of Cowper's gland is a very rare cancer. This case represents the 9th case in the medical literature. As such, there are no phase II or phase III trials to guide treatment. In this article, we report the successful treatment of a patient over a 7-year period guided solely by molecular profiling. Through multiple cycles to treatment, the cancer was controlled using drugs targeting c-kit, as the cancer steadily increased the expression of c-kit. This report also documents the use of a novel drug combination based on sunitinib that was well tolerated and may warrant testing in other c-kit-dependent cancers.

(C) 2014 S. Karger AG, Basel
\end{abstract}

\section{Introduction}

Cancer of Cowper's gland is a rare cancer with fewer than 10 recorded cases [1-6]. The literature is composed of case reports, primarily predating the modern era of chemotherapy. This means making treatment decisions without randomized phase III or even phase II trials.

The reported cases of Cowper's gland carcinoma have all been adenoid cystic carcinoma (AdCC), and treatment effective against AdCC arising in other organs might be used. However, AdCC is uncommon or rare in each of the organs in which it is found. This pathology is most commonly found in salivary gland cancers, which constitute less than $5 \%$ 
Myers et al.: Metastatic Cancer of Cowper's Gland: A Rare Cancer Managed

of all head and neck cancers. As a result, there are no randomized phase III clinical trials with sufficient statistical power to guide management of AdCC at any organ site. Even phase II clinical trials are limited in number, and none has yielded impressive therapeutic results. Most clinical studies in AdCC show only disease stabilization. Objective tumor responses are uncommon [7-16]. Furthermore, the available information suggests there may be significant differences in drug effectiveness in AdCC arising in different organ sites [17-19].

An alternate approach to uncommon cancers is to let molecular profiling guide selection of drugs for systemic therapy. The attraction of this approach is that the treatment is selected based on known mechanisms of drug action. Furthermore, accumulation of such information is likely to shed light on how AdCC at various organ sites differs in ways that can be used not only to guide therapy of individual patients, but also to guide clinical trial design. In this article, we report the results of this approach with a case of Cowper's gland AdCC.

\section{Case Report}

The patient initially presented with pelvic pain and rectal discomfort. CT showed a prostate mass. Based on a core biopsy, he was diagnosed with Cowper's gland AdCC.

When the patient initially presented for treatment, we faced the quandary posed by the lack of clinical trial data on this very rare disease. The options were no treatment at all or to let molecular profiling guide treatment choices. This issue was discussed in detail with the patient and his wife, and they elected to proceed with treatment. The case and the treatment quandary were presented to the hospital tumor board, and the decision to start treatment was agreed upon. At every step in the course of the treatment outlined, decisions were solely based on the treatment options that seemed to offer the patient the best balance between cancer control and quality of life.

The patient was initially treated with pelvic exenteration on February 26, 2003. However, the surgical margins were positive, and he received adjuvant radiation, cisplatin and taxol. He remained disease free for just under 3 years, until he experienced recurrence on January 11, 2006, with a mass in the surgical bed. A biopsy confirmed recurrent AdCC. Immunohistochemistry documented the presence of c-kit and epidermal growth factor receptor (EGFR). No treatment was offered. By July 2006, the patient had documented liver metastasis seen on CT, and these lesions were biopsy positive for AdCC. The mass in the surgical bed was removed and the liver lesion was treated with cryoablation.

While AdCC can often progress slowly, this patient demonstrated rapid growth and spread of his disease. By September 2006, he had developed a $1.3 \times 1.3-\mathrm{cm}$ lung lesion and an additional $2 \times 2$-cm liver lesion (fig. 1a). In October 2006, based on the initial immunochemistry detection of c-kit, the patient was started on a sunitinib-based combination (50 mg daily) because of its activity against c-kit as well as its impact on vascular endothelial growth factor (VEGF) and platelet-derived growth factor (PDGF) receptor kinase activity. The histone deacetylase (HDAC) inhibitor, valproic acid $500 \mathrm{mg}$, was added twice a day; thalidomide $50 \mathrm{mg}$ and sargramostim $250 \mu \mathrm{g}$ were added daily. The rationale for this combination is discussed below.

By December of 2006, six weeks after initiation of therapy, the lung lesion had disappeared, but the liver lesion remained stable (fig. 1b). Three months later (March 2007), the liver lesion had increased marginally to $2.5 \times 2.0 \mathrm{~cm}$. At this point, the liver lesion was treated with cryoablation. At the end of May 2009, the patient had a screening colonoscopy with perforation of the bowel, leading to sepsis and suspension of cancer treatment for almost 1 month. During this time, he developed a rapidly progressing lesion at L4. Thus, the sunitinib- 
Myers et al.: Metastatic Cancer of Cowper's Gland: A Rare Cancer Managed Successfully by Molecular Profiling

based combination resulted in a progression-free survival of almost 2.5 years, during which he was able to work fulltime as a dentist. The sunitinib-based combination was restarted but proved ineffective. Because of EGFR expression, he was treated in turn with erlotinib and lapatinib without clinical benefit but with progression of pulmonary metastases.

At this point, the surgical specimen from May 2009 (metastatic carcinoma from T6 epidural space) was submitted to Caris Life Sciences, Phoenix, Ariz., USA, for more detailed analysis (Target Now tumor profiling). This specimen showed overexpression of TOPO1 (fig. $2 a)$, suggesting sensitivity to irinotecan. As a result, he was started on cycles of irinotecan $125 \mathrm{mg} / \mathrm{m}^{2}$ per week $\times 4$, followed by 2 weeks off. His disease remained stable for 10 months before he progressed.

The Caris Target Now analysis of the July 2010 sacral biopsy specimen had also shown continued expression of c-kit (fig. 2b). For this reason, in September 2010 he was started on imatinib $400 \mathrm{mg}$ per day. He showed stable disease on imatinib for 9 months until he progressed with bone lesions leading to cord compression, which was managed with surgical resection.

In November 2011, he was started on gemcitabine based on overexpression of mRNA for deoxycytidine kinase. He did not respond, perhaps due to overexpression of RRM1, which has been linked to gemcitabine resistance [20]. In February 2012, he was started on liposomal doxorubicin because of overexpression of TOPO2B on RNA microarray. He derived substantial pain relief, with pain levels going from 7-8 to 2-3/10. The palpable mass arising from the thoracic spine showed marked reduction in size, without healing in the corresponding bone. In contrast, his renal lesions progressed on treatment. Doxil was terminated in August 2012.

Molecular profiling of a spinal (T6 epidural) tumor performed in August 2012 revealed overexpression of SRC mRNA, and the patient has been receiving dasatinib with good cancer control. He had an isolated site of progression in the spine that was successfully debulked surgically, after which dasatinib was continued. Additionally, molecular profiling of kidney metastasis of the AdCC revealed no mutations in KRAS, PIK3CA and BRAF genes.

\section{Discussion}

AdCCs of the salivary glands and breast have been associated with the presence of $M Y B-N F I B$ fusion, resulting in overexpression of MYB mRNA transcript, which was observed in our case as well (67 times the normal salivary gland control using Illumina microarray methodology) [21-25]. Pathologically, these cancers are composed of a dual cell population of luminal and myoepithelial cells. These cancers are often c-kit positive, but c-kit expression is commonly limited to the luminal cell component [21, 26, 27]. Additionally, c-kit is only rarely activated through gene mutations in AdCC, and no mutations were observed in our case [28]. The $5^{\prime}$ end of the c-kit gene contains MYB response elements, and MYB has been shown to up-regulate c-kit expression. Despite these findings, the role of c-kit (and possibly its ligand) remains to be established at a molecular level in the biology of these cancers.

By the fall of 2006 when we first encountered this patient, known treatment options for Cowper's gland carcinoma had been exhausted. Furthermore, over a 3-month period, he had shown rapid cancer progression in the lungs and liver, suggesting a relatively poor prognosis. The presence of c-kit overexpression was the only clue available upon which to design a treatment program, and we chose to target this protein. Subsequent analysis showed overexpression of PDGF-C and PDGFRA at the RNA level and PDGF receptor by immunohistochemistry. 
For his initial treatment program, we selected sunitinib because of its activity against c-kit $[29,30]$. We elected to combine this drug with agents that might amplify the actions of sunitinib. At the time the combination was assembled, it was known that sunitinib reduced tumor-induced immunosuppression. Subsequently, sunitinib has been shown to diminish myeloid-derived suppressor cells and regulatory T cells [31,32]. We elected to add low-dose thalidomide and sargramostim to further enhance any beneficial impact sunitinib might have on immune function.

Sunitinib also blocks angiogenesis via its capacity to block VEGF receptor and PDGF receptor, and his tumor expressed both PDGF receptor and its ligand. In this combination, valproic acid may have contributed because it has been reported to reduce expression of both VEGF receptor and VEGF. Additionally, valproic acid has been reported to be selectively toxic to c-kit+ GIST compared to c-kit- GIST [33].

This combination was very well tolerated and allowed the patient to continue to work at his chosen profession of dentistry. Additionally, it resulted in a partial response that lasted approximately 2.5 years. This combination may warrant additional testing in c-kit-positive malignancies.

Subsequent to this initial response, he has had disease stabilization and relief of pain from irinotecan, imatinib and liposomal doxorubicin, but no partial or complete remissions. Each of these treatments was chosen based on molecular profiling. The patient benefited from 3 out of the 4 treatments based on molecular profiling performed on the May 2009 surgical specimen. We must not overlook the undeniable contribution of the multiple surgeries which provided both symptomatic relief and samples for profiling, but also contributed to the prolonged survival of the patient. Whether or not the profiling was simply associated with or actually caused the responses seen cannot be determined outside the context of a randomized controlled trial. However, continuous profiling of the disease provided therapeutic monitoring and therapy adjustments, and also showed remarkably subtle changes in monitored biomarkers during the evolution/drug selection pressure of the disease process.

Despite having a cancer that rapidly progressed off treatment, our patient remains alive 6 years after progressing through known treatment options for Cowper's gland carcinoma. We conclude that for rare cancers such as this, treatment selection based on molecular profiling may well prove to be a reasonable option.

\section{References}

1 Arduino LJ, Nuesse WE: Carcinoma of Cowper's gland: case report. J Urol 1969;102:224-229.

- Bourque JL, Charghi A, Gauthier GE, et al: Primary carcinoma of Cowper's gland. J Urol 1970;103:758-761.

-3 Carpenter AA, Bernardo JR Jr: Adenoid cystic carcinoma of Cowper's gland: case report. J Urol 1971;106: 701-703.

4 Derrick FC Jr, Lynch KM Jr: Cowper's gland carcinoma. Report of a case. J S C Med Assoc 1968;64:82-84.

5 Small JD, Albertsen PC, Graydon RJ, et al: Adenoid cystic carcinoma of Cowper's gland. J Urol 1992;147:699701.

6 Keen MR, Golden RL, Richardson JF, et al: Carcinoma of Cowper's gland treated with chemotherapy. J Urol 1970;104:854-859.

7 Argiris A, Ghebremichael M, Burtness B, et al: A phase 2 trial of bortezomib followed by the addition of doxorubicin at progression in patients with recurrent or metastatic adenoid cystic carcinoma of the head and neck: a trial of the Eastern Cooperative Oncology Group (E1303). Cancer 2011;117:3374-3382.

8 Chau NG, Hotte SJ, Chen EX, et al: A phase II study of sunitinib in recurrent and/or metastatic adenoid cystic carcinoma (ACC) of the salivary glands: current progress and challenges in evaluating molecularly targeted agents in ACC. Ann Oncol 2012;23:1562-1570.

-9 Mattox DE, Von Hoff DD, Balcerzak SP: Southwest Oncology Group study of mitoxantrone for treatment of patients with advanced adenoid cystic carcinoma of the head and neck. Invest New Drugs 1990;8:105-107. 


\section{Case Reports in Oncology}

\begin{tabular}{l|l}
\hline \multicolumn{2}{l}{ Case Rep Oncol 2014;7:52-57 } \\
\hline DOI: $10.1159 / 000357972$ & $\begin{array}{l}\text { C 2014 S. Karger AG, Basel } \\
\text { www.karger.com/cro }\end{array}$ \\
\hline
\end{tabular}

Myers et al.: Metastatic Cancer of Cowper's Gland: A Rare Cancer Managed Successfully by Molecular Profiling

10 Jensen AD, Nikoghosyan A, Hinke A, et al: Combined treatment of adenoid cystic carcinoma with cetuximab and IMRT plus C12 heavy ion boost: ACCEPT [ACC, Erbitux(R) and particle therapy]. BMC Cancer 2011;11:70.

-11 Hotte SJ, Winquist EW, Lamont E, et al: Imatinib mesylate in patients with adenoid cystic cancers of the salivary glands expressing c-kit: a Princess Margaret Hospital phase II consortium study. J Clin Oncol 2005;23:585-590.

12 Ghosal N, Mais K, Shenjere P, et al: Phase II study of cisplatin and imatinib in advanced salivary adenoid cystic carcinoma. Br J Oral Maxillofac Surg 2011;49:510-515.

13 van Herpen CM, Locati LD, Buter J, et al: Phase II study on gemcitabine in recurrent and/or metastatic adenoid cystic carcinoma of the head and neck (EORTC 24982). Eur J Cancer 2008;44:2542-2545.

$\checkmark 14$ Pfeffer MR, Talmi Y, Catane R, et al: A phase II study of Imatinib for advanced adenoid cystic carcinoma of head and neck salivary glands. Oral Oncol 2007;43:33-36.

$\checkmark 15$ Seethala RR, Hunt JL, Baloch ZW, et al: Adenoid cystic carcinoma with high-grade transformation: a report of 11 cases and a review of the literature. Am J Surg Pathol 2007;31:1683-1694.

16 Verweij J, de Mulder PH, de Graeff A, et al: Phase II study on mitoxantrone in adenoid cystic carcinomas of the head and neck. EORTC Head and Neck Cancer Cooperative Group. Ann Oncol 1996;7:867-869.

17 Marchio C, Weigelt B, Reis-Filho JS: Adenoid cystic carcinomas of the breast and salivary glands (or 'The strange case of Dr. Jekyll and Mr. Hyde' of exocrine gland carcinomas). J Clin Pathol 2010;63:220-228.

-18 Vranic S, Bender R, Palazzo J, et al: A review of adenoid cystic carcinoma of the breast with emphasis on its molecular and genetic characteristics. Hum Pathol 2013;44:301-309.

19 Wetterskog D, Lopez-Garcia MA, Lambros MB, et al: Adenoid cystic carcinomas constitute a genomically distinct subgroup of triple-negative and basal-like breast cancers. J Pathol 2012;226:84-96.

20 Gong W, Dong J, et al: RRM1 expression and clinical outcome of gemcitabine-containing chemotherapy for advanced non-small-cell lung cancer: a meta-analysis. Lung Cancer 2012;75:374-380.

21 Bell D, Roberts D, Kies M, et al: Cell type-dependent biomarker expression in adenoid cystic carcinoma: biologic and therapeutic implications. Cancer 2010;116:5749-5756.

22 Bell D, Roberts D, Karpowicz M, et al: Clinical significance of Myb protein and downstream target genes in salivary adenoid cystic carcinoma. Cancer Biol Ther 2011;12:569-573.

23 Brill LB 2nd, Kanner WA, Fehr A, et al: Analysis of MYB expression and MYB-NFIB gene fusions in adenoid cystic carcinoma and other salivary neoplasms. Mod Pathol 2011;24:1169-1176.

24 Ratajczak MZ, Perrotti D, Melotti P, et al: Myb and ets proteins are candidate regulators of c-kit expression in human hematopoietic cells. Blood 1998;91:1934-1946.

25 Persson M, Andren Y, Moskaluk CA, et al: Clinically significant copy number alterations and complex rearrangements of MYB and NFIB in head and neck adenoid cystic carcinoma. Genes Chromosomes Cancer 2012;51:805-817.

26 Andreadis D, Epivatianos A, Poulopoulos A, et al: Detection of C-KIT (CD117) molecule in benign and malignant salivary gland tumours. Oral Oncol 2006;42:57-65.

27 Jeng YM, Lin CY, Hsu HC: Expression of the c-kit protein is associated with certain subtypes of salivary gland carcinoma. Cancer Lett 2000;154:107-111.

28 Vila L, Liu H, Al-Quran SZ, et al: Identification of c-kit gene mutations in primary adenoid cystic carcinoma of the salivary gland. Mod Pathol 2009;22:1296-1302.

-29 Finke JH, Rini B, Ireland J, et al: Sunitinib reverses type-1 immune suppression and decreases T-regulatory cells in renal cell carcinoma patients. Clin Cancer Res 2008;14:6674-6682.

30 Gravalos C, Grande E, Gasent JM: The potential role of sunitinib in gastrointestinal cancers other than GIST. Crit Rev Oncol Hematol 2010;76:36-43.

-31 Ko JS, Zea AH, Rini BI, et al: Sunitinib mediates reversal of myeloid-derived suppressor cell accumulation in renal cell carcinoma patients. Clin Cancer Res 2009;15:2148-2157.

-32 Ozao-Choy J, Ma G, Kao J, et al: The novel role of tyrosine kinase inhibitor in the reversal of immune suppression and modulation of tumor microenvironment for immune-based cancer therapies. Cancer Res 2009;69:2514-2522.

Muhlenberg T, Zhang Y, Wagner AJ, et al: Inhibitors of deacetylases suppress oncogenic KIT signaling, acetylate HSP90, and induce apoptosis in gastrointestinal stromal tumors. Cancer Res 2009;69:6941-6950. 


\section{Case Reports in Oncology}
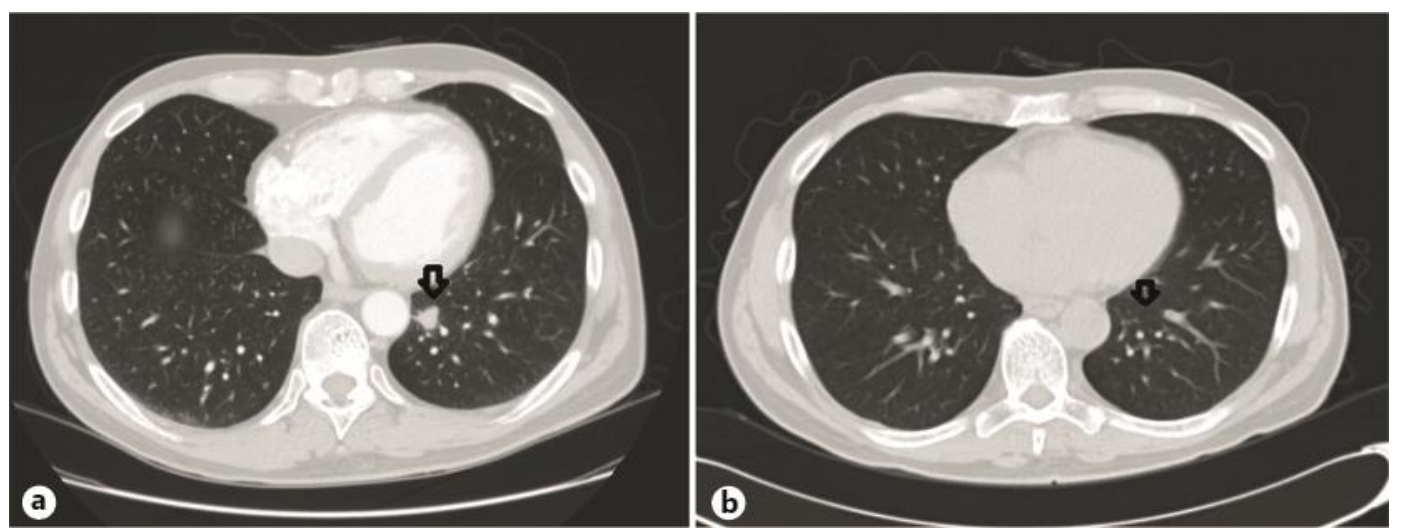

Fig. 1. Status of the pulmonary metastases prior to the treatment with the sunitinib-based combination (a) and in December 2006 after a response to the treatment (b).

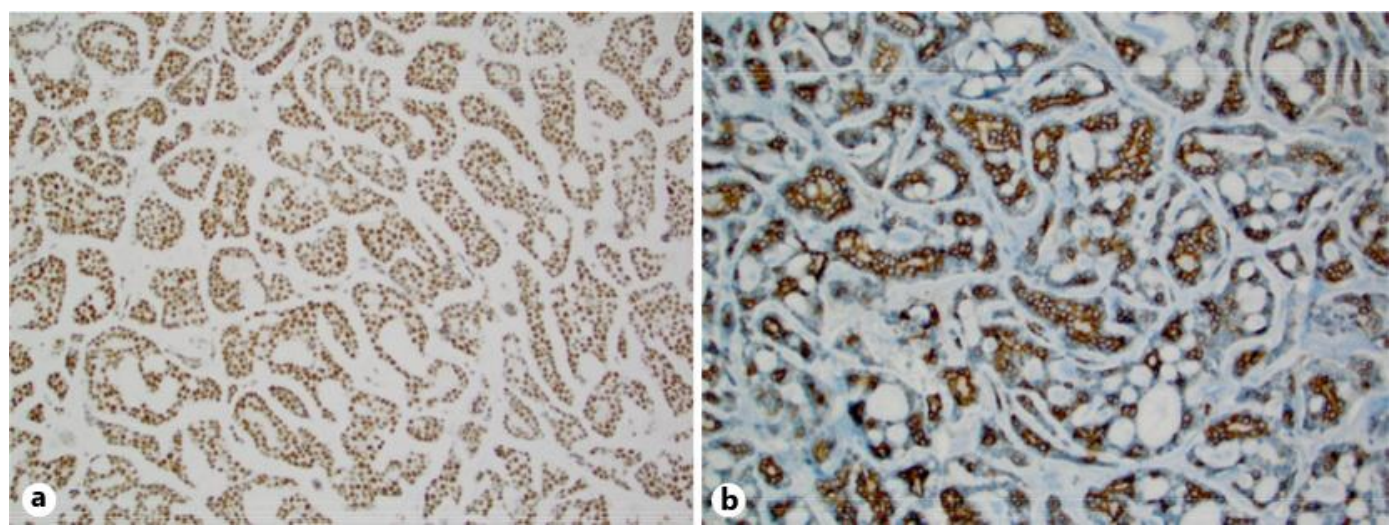

Fig. 2. a Positive IHC staining for TOPO1 expression. b Positive IHC staining for c-kit. 